\title{
Analysis of the effect of different absorber materials and loading on the shielding effectiveness of a metallic enclosure
}

\author{
S. Parr ${ }^{1}$, H. Karcoon ${ }^{1}$, S. Dickmann ${ }^{1}$, and R. Rambousky ${ }^{2}$ \\ ${ }^{1}$ Faculty of Electrical Engineering, Helmut-Schmidt-University/University of the Federal Armed Forces Hamburg, Germany \\ ${ }^{2}$ Bundeswehr Research Institute for Protective Technologies and NBC Protection (WIS) Munster, Germany
}

Correspondence to: S. Parr (stefan.parr@hsu-hh.de)

Received: 24 November 2014 - Revised: 26 February 2015 - Accepted: 4 March 2015 - Published: 3 November 2015

\begin{abstract}
Metallic rooms as part of a complex system, like a ship, are necessarily connected electromagnetically via apertures and cables to the outside. Therefore, their electromagnetic shielding effectiveness (SE) is limited by ventilation openings, cable feed-throughs and door gaps. Thus, electronic equipment inside these rooms is susceptible to outer electromagnetic threats like IEMI ${ }^{1}$. Dielectric or magnetic absorber inside such a screened room can be used in order to prevent the SE from collapsing at the resonant frequencies. In this contribution, the effect of different available absorber materials is compared, as well as other properties like weight and workability. Furthermore, parameter variations of the absorber as well as the effect of loading in form of metallic and dielectric structures on the SE are analyzed.
\end{abstract}

\section{Introduction}

Inside metallic, empty, perfectly conducting and cuboid rooms or enclosures, resonances are excited by external fields at the frequencies

$$
F_{(m, n, p)}=\frac{c}{2} \sqrt{\left(\frac{m}{a}\right)^{2}+\left(\frac{n}{b}\right)^{2}+\left(\frac{p}{d}\right)^{2}}
$$

with $a, b$ and $d$ : dimensions, $c$ : speed of light in free space, $m, n$ and $p$ : positive integers, one of which may be zero (Dawson et al., 2001). This results in large spectral and spatial variations in field levels up to $45 \mathrm{~dB}$ (Izzat et al., 1998). Electronic equipment inside the room can thus be impaired due to the high field strengths at the resonant frequencies. The SE at the resonances can be improved by lining the inner walls with absorbing material (Olyslager et al., 1999).

\footnotetext{
${ }^{1}$ Intentional Electromagnetic Interference
}

In this contribution, two studies are carried out. First, different absorber materials are compared with respect to their damping property, flammability, workability, weight and price. Therefore, a cuboid screened enclosure with dimensions of $40 \mathrm{~cm}$ is analyzed in the frequency range of 400 to $1000 \mathrm{MHz}$ via simulation and measurement. It is illuminated by a TEM wave which couples in through an aperture at its front side. The inner back side is tiled with a layer of different absorber materials: polyurethane-carbon foam, ferrite tiles and two different types of ferrite composite absorber. The SE is determined via simulation and measurement. For the simulation, knowledge about the dielectric and magnetic properties of the absorber materials is necessary. This is provided by a reflection and transmission measurement inside a coaxial transmission line.

In the second study, the SE of a full size room with a door gap as aperture is investigated numerically. As the field strength inside the resonator is spatially varying at the resonant frequencies, the SE is calculated via the mean energy density. Different parameter variations of the absorber like thickness and number are carried out in the frequency range from 40 to $100 \mathrm{MHz}$. Furthermore, the impact of metallic and dielectric loading inside the enclosure on SE is determined.

\section{Comparison of different absorbing materials}

\subsection{Permittivity and permeability of the absorber}

First, the influence of absorber inside a screened enclosure on the SE is analyzed for different materials. In order to carry out numeric calculations, the complex permittivity and per- 
Table 1. Minimum electric shielding effectiveness of the enclosure with absorber.

\begin{tabular}{lrrrrr}
\hline $\begin{array}{l}\text { Absorber } \\
\text { material } \\
\text { (thickness })\end{array}$ & ferrite & $\begin{array}{r}\text { polyurethane- } \\
\text { carbon } \\
(20.5 \mathrm{~mm})\end{array}$ & $\begin{array}{r}\text { silicon- } \\
\text { ferrite } \\
(2 \mathrm{~mm})\end{array}$ & $\begin{array}{r}\text { polyethylene- } \\
\text { ferrite } \\
(4 \mathrm{~mm})\end{array}$ & $\begin{array}{r}\text { polyethylen- } \\
\text { ferrite } \\
(2 \mathrm{~mm})\end{array}$ \\
\hline $\begin{array}{l}\text { Measurement } \\
\text { Simulation }\end{array}$ & $30 \mathrm{~dB}$ & $24 \mathrm{~dB}$ & $17 \mathrm{~dB}$ & $30 \mathrm{~dB}$ & $28 \mathrm{~dB}$ \\
& $21 \mathrm{~dB}$ & $20 \mathrm{~dB}$ & $14 \mathrm{~dB}$ & $34 \mathrm{~dB}$ & $32 \mathrm{~dB}$ \\
\hline
\end{tabular}

Table 2. Comparison of different properties of the absorber materials.

\begin{tabular}{|c|c|c|c|c|c|}
\hline & ferrite $5.5 \mathrm{~mm}$ & $\begin{array}{l}\text { polyurethane- } \\
\text { carbon } 20 \mathrm{~mm}\end{array}$ & $\begin{array}{l}\text { silicon-ferrite } \\
2 \mathrm{~mm}\end{array}$ & $\begin{array}{l}\text { polyethylene- } \\
\text { ferrite } 4 \mathrm{~mm}\end{array}$ & $\begin{array}{l}\text { polyethylene- } \\
\text { ferrite } 2 \mathrm{~mm}\end{array}$ \\
\hline Price & $400 € \mathrm{~m}^{-2}$ & $120 € \mathrm{~m}^{-2}$ & $1139 € \mathrm{~m}^{-2}$ & $2831 € \mathrm{~m}^{-2}$ & $1910 € \mathrm{~m}^{-2}$ \\
\hline $\begin{array}{l}\text { Damping quality for } \\
400 \text { to } 1000 \mathrm{MHz}\end{array}$ & good & fair & poor & good & good \\
\hline Flammability & not inflammable & $\begin{array}{l}\text { inflammable } \\
\text { (flame-resistant } \\
\text { version available) }\end{array}$ & not inflammable & not inflammable & not inflammable \\
\hline Workability & poor & good & good & good & good \\
\hline Weight per area & $27.8 \mathrm{~kg} \mathrm{~m}^{-2}$ & $0.96 \mathrm{~kg} \mathrm{~m}^{-2}$ & $6.3 \mathrm{~kg} \mathrm{~m}^{-2}$ & $14.8 \mathrm{~kg} \mathrm{~m}^{-2}$ & $7.4 \mathrm{~kg} \mathrm{~m}^{-2}$ \\
\hline
\end{tabular}

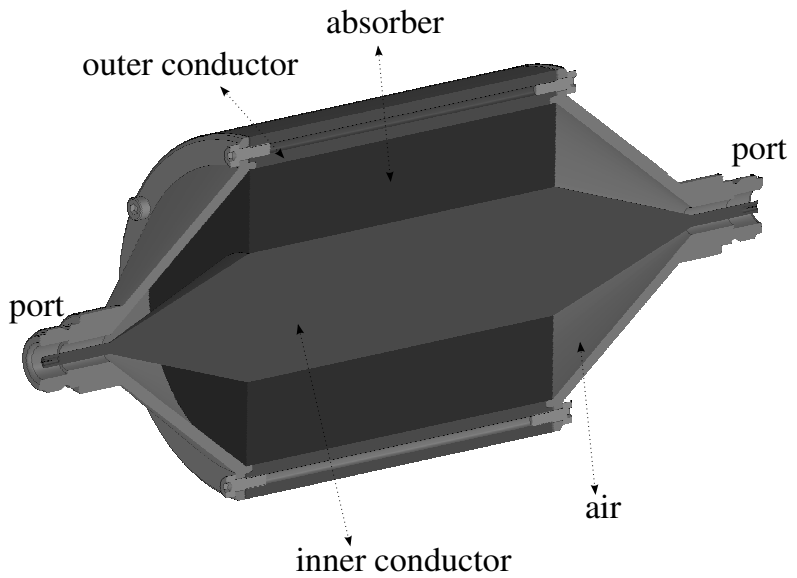

Figure 1. Coaxial line experiment setup for determination of the complex permittivity.

meability

$$
\begin{gathered}
\varepsilon_{\mathrm{r}}=\varepsilon_{\mathrm{r}}^{\prime}-j \varepsilon_{\mathrm{r}}^{\prime \prime} \\
\mu_{\mathrm{r}}=\mu_{\mathrm{r}}^{\prime}-j \mu_{\mathrm{r}}^{\prime \prime}
\end{gathered}
$$

of the absorber have to be known. They are determined via a coaxial line experiment measuring the reflection and transmission coefficients with a network analyzer. The setup of the coaxial line with the absorber inserted is shown in Fig. 1. The analyzed absorber materials include polyurethane-carbon foam as an dielectric absorber, ferrite tiles, silicon-ferrite and polyethylene-ferrite as magnetic ab-

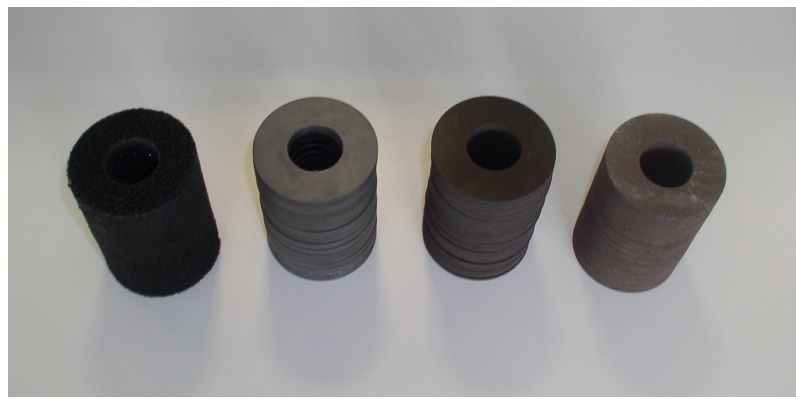

Figure 2. Absorber samples for the coaxial line experiment. From left to right: polyurethane-carbon, ferrite, silicon-ferrite, polyethylene-ferrite.

sorber. The pre-cut absorber samples are shown in Fig. 2. The permittivity and permeability are calculated using the Nicolson-Ross-Weir (NRW) algorithm (Nicolson and Ross, 1970) from the $S$ parameters. A measurement of the empty line yields reasonable results for permittivity and permeability of air up to $1 \mathrm{GHz}$. Above, higher order modes spoil the measurement (Ihsan et al., 2011). The extracted values for ferrite and polyurethane-carbon are shown in Fig. 3.

\subsection{Shielding Effectiveness of the resonator with and without absorber}

A screened enclosure in form of a cube with dimensions of approximately $40 \mathrm{~cm}$ and a circular aperture with a radius $r_{0}$ of $15 \mathrm{~mm}$ at its front side is analyzed. The thickness of the 


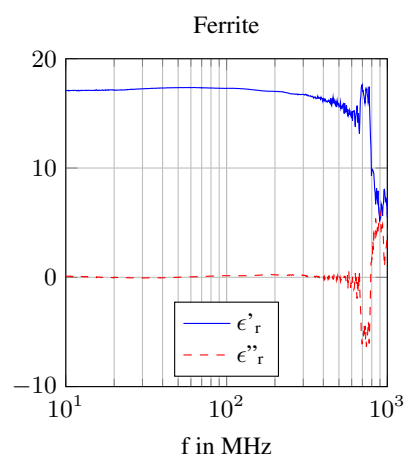

Polyurethane foam + Carbon

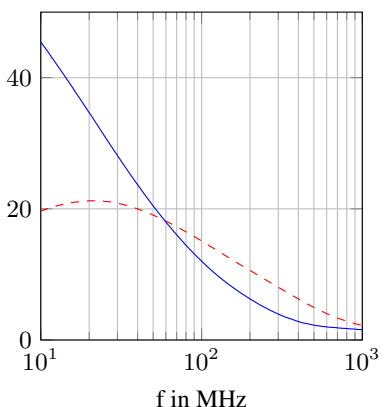

Ferrite

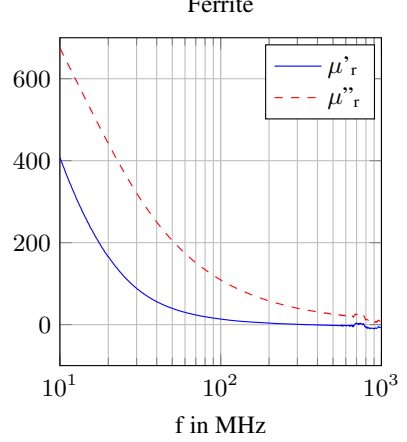

Polyurethane foam + Carbon

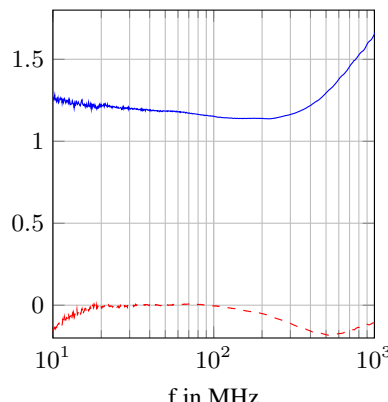

Figure 3. Permittivity and Permeability of ferrite and polyurethanecarbon absorber.

Table 3. Minimum wavelength inside the absorber in the frequency range 40 to $100 \mathrm{MHz}$.

\begin{tabular}{ll}
\hline Material & $\lambda_{\min }$ in $\mathrm{m}$ \\
\hline vacuum & 3 \\
polyurethane-carbon & 0.63 \\
ferrite & 0.069 \\
silicon-ferrite & 0.70 \\
polyethylen-ferrite & 0.38 \\
\hline
\end{tabular}

absorber covering the inner back wall depends on the used material. The box is illuminated with a TEM wave and its electric shielding effectiveness $\mathrm{SE}_{\mathrm{el}}$ is defined as

$\mathrm{SE}_{\mathrm{el}}=20 \times \log _{10} \frac{E_{0}}{E_{1}}$ in $\mathrm{dB}$.

with $E_{0}$ : electric field in absence of the shield, $E_{1}$ : electric field inside the shield. $\mathrm{SE}_{\mathrm{el}}$ is determined via measurement and simulation in the frequency range of $400 \mathrm{MHz}$ to $1 \mathrm{GHz}$. The lower limit is chosen in such a way that the first resonance at $529 \mathrm{MHz}$ is covered. A GTEM cell is used as a source for a TEM electromagnetic wave for the measurement (Parr et al., 2012). The simulation is done using the FiniteElement-Method within the software FEKO. The minimum of $\mathrm{SE}_{\mathrm{el}}$ of the empty resonator at the analyzed frequencies is at $10 \mathrm{~dB}$. It is improved by the different absorbers reaching values shown in Table 1.

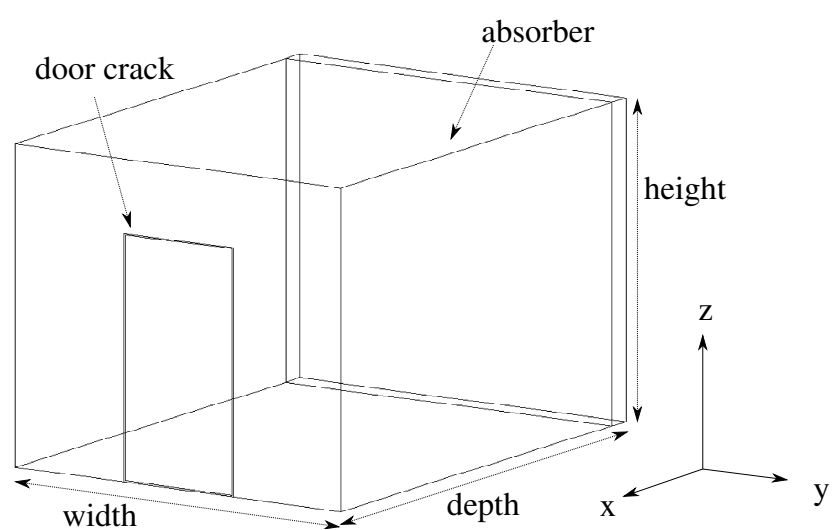

Figure 4. Screened room with door gap.

Table 4. Minimum value for $\mathrm{SE}_{\mathrm{em}}$ with different absorber thicknesses $e$.

\begin{tabular}{lrrrr}
\hline$e$ & $0 \mathrm{~cm}$ & $5 \mathrm{~cm}$ & $10 \mathrm{~cm}$ & $20 \mathrm{~cm}$ \\
\hline $\mathrm{SE}_{\min }$ & $-26 \mathrm{~dB}$ & $-21 \mathrm{~dB}$ & $-12 \mathrm{~dB}$ & $-2 \mathrm{~dB}$ \\
\hline
\end{tabular}

\subsection{Consideration of other absorber properties}

Not only the ability to improve the SE, but also other absorber properties like flammability, workability, weight and price have to be considered for practical purposes. They are given for the different materials in Table 2. Ferrite has the best damping properties, but lacks workability and is heavy, whereas polyurethane-carbon absorber shows an overall decent performance.

\section{Parameter variations of the absorber and loading}

\subsection{Model for the numerical calculations}

In this section, different parameter variations of the absorber geometry inside a screened room are carried out, and the effect of dielectric and metallic structures inside is considered. Therefore, the SE of a screened room with dimensions $4 \mathrm{~m}$ (depth) $\times 3 \mathrm{~m}$ (width) $\times 2.6 \mathrm{~m}$ (height) as shown in Fig. 4 is analyzed via FEM simulation. As aperture a round about door gap is assumed, representing a shielded door, that is not closed properly. The incoming TEM wave travels in $x$ direction and its electric field is polarized $45^{\circ}$ to the $z$ axis, in order to excite all modes. As the field levels inside the room vary significantly in space at the resonant frequencies, the shielding effectiveness $\mathrm{SE}_{\mathrm{em}}$ is calculated via the mean energy density $w$ of the electromagnetic field:

$\mathrm{SE}_{\mathrm{em}}=10 \log _{10} \frac{\bar{w}_{0}}{\bar{w}_{1}} \mathrm{~dB}$

with $\overline{w_{0}}$ : mean electromagnetic energy density in absence of the shield and $\overline{w_{1}}$ : mean electromagnetic energy density 


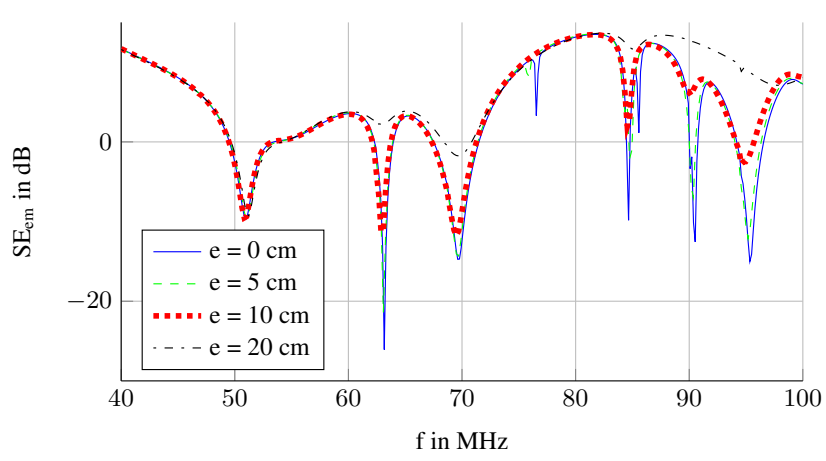

Figure 5. CEM results for $\mathrm{SE}_{\mathrm{em}}$ for different polyurethane-carbon absorber thicknesses $e$.

Table 5. Minimum value for $\mathrm{SE}_{\mathrm{em}}$ with different number of walls lined with $10 \mathrm{~cm}$ absorber.

\begin{tabular}{lllll}
\hline $\begin{array}{l}\text { walls lined } \\
\text { with absorber }\end{array}$ & $\begin{array}{l}\text { without } \\
\text { absorber }\end{array}$ & $\begin{array}{l}\text { rear } \\
\text { wall }\end{array}$ & $\begin{array}{l}\text { rear wall } \\
\text { and ceiling }\end{array}$ & $\begin{array}{l}\text { ceiling, rear and } \\
\text { side walls }\end{array}$ \\
\hline $\mathrm{SE}_{\min }$ & $-26 \mathrm{~dB}$ & $-12 \mathrm{~dB}$ & $-6 \mathrm{~dB}$ & $-3 \mathrm{~dB}$ \\
\hline
\end{tabular}

inside the shield. It is calculated as the average value over 240 points with a spacing of $0.5 \mathrm{~m}$. An adaptive frequency sampling is chosen with a minimum frequency increment of $150 \mathrm{kHz}$ in the range of 40 to $100 \mathrm{MHz}$, covering the first resonance of the room at $62.5 \mathrm{MHz}$.

Due to its high permittivity and/or permeability, the absorber region is meshed more densely. The minimum wavelength inside the absorber in the analyzed frequency interval for the different materials is shown in Table 3. Not only the absorber region is meshed densely but also the adjacent metallic surfaces of the enclosure. These are numerically solved with the Methods of Moments, which leads to high time and memory consumption in the case of ferrite.

\subsection{Parameter variations of the absorber}

As absorber material polyurethane-carbon is chosen. At first, the thickness of the absorber layer $e$ at the rear of the room is varied. The $\mathrm{CEM}^{2}$ results for $\mathrm{SE}_{\mathrm{em}}$ for values for $e$ of 5,10 and $20 \mathrm{~cm}$ are shown in Fig. 5. The minimum $\mathrm{SE}_{\mathrm{em}}$ without absorber is $-26 \mathrm{~dB}$ at $62.5 \mathrm{MHz}$, which corresponds to the first resonance of the room (110). The resonance at $51 \mathrm{MHz}$ is caused by the door gap and is therefore not affected by the absorber. $\mathrm{SE}_{\min }$, the minimum value for $\mathrm{SE}_{\mathrm{em}}$ in the analyzed frequency region for different absorber thicknesses is shown in Table 4.

Furthermore, the number of walls that are lined with absorber is varied. As a result, the resonant frequencies of the room shift slightly, as the resonator gets electrically larger. The minimum value for $\mathrm{SE}_{\mathrm{em}}$ is shown in Table 5 .

\footnotetext{
${ }^{2}$ Computational Electromagnetics
}

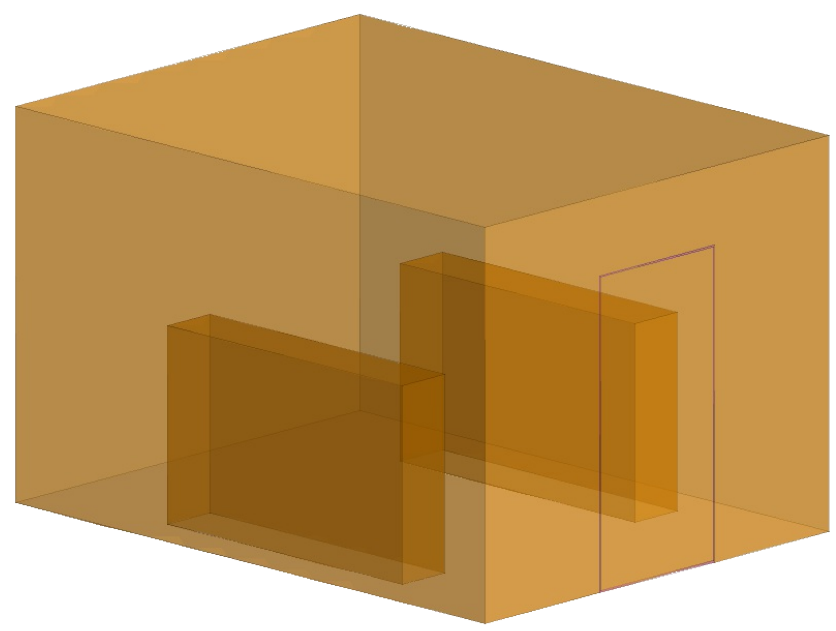

Figure 6. Screened room with metallic structures (terminals).

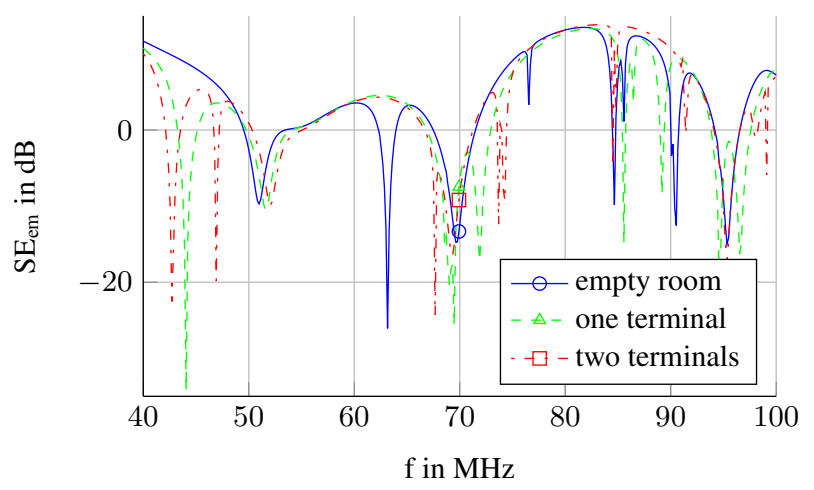

Figure 7. CEM results for SE with and without terminals inside the room.

\subsection{Effect of dielectric and metallic structures inside the room}

In order to distinguish between the effects of dielectric and metallic structures inside the room on SE, both cases are analyzed separately. At first, metallic structures in the form of two cuboids, named here terminals, are inserted in the room model as depicted in Fig. 6. The numeric results for $\mathrm{SE}_{\mathrm{em}}$ with none, one and both terminals are shown in Fig. 7. As a result, the metallic structures shift the resonant frequencies and cause additional resonances in the low frequency region.

Next, the effect of dielectric structures in form of persons is considered, that are modeled as columns with electromagnetic properties of human muscle. As a reasonable assumption, two persons are modeled inside the room (Fig. 8). The numeric results in Fig. 9 show, that the (110) and (210) resonances are completely damped, because their electric field is polarized in $z$ direction, parallel to the columns in the centre of the room. The value for $\mathrm{SE}_{\mathrm{em}}$ at other resonances however is lower with the dielectrics inside the room. 


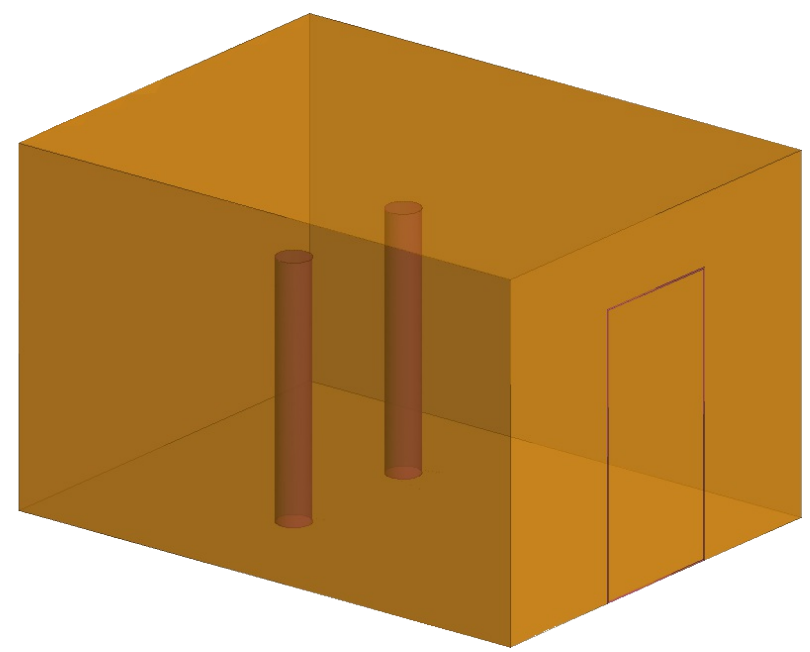

Figure 8. Screened room with dielectric structures (persons).

\section{Conclusions}

In the framework of an electromagnetic analysis of a complex system with consideration of resonant room and enclosure structures, two studies have been caried out. First, various absorber materials have been compared with respect to their effect on the SE in the frequency range of 400 to $1000 \mathrm{MHz}$. Ferrite and a composite ferrite absorber have the best damping properties, improving the minimum SE from 10 to $30 \mathrm{~dB}$, while polyurethane-carbon foam has significant advantages in price, weight and workability. Then, the effect of absorber on the resonances of a metallic room has been analyzed, and the improvement in SE quantified with different parameter variations. It shows, that a $10 \mathrm{~cm}$ polyurethane-carbon layer at the rearside of the room improves the minimum value for SE from -26 to $-12 \mathrm{~dB}$. Finally, the effect of loading on the resonance behavior has been considered. Metallic structures inside the room cause additional resonances below the first room resonance, and therefore reduce the SE. The effect of dielectric structures on SE depends on the electric field distribution of the resonant modes. Both, metallic and dielectric loading, result in a slight shift of the resonant frequencies. The results show, that the susceptibility of a complex system to an outer electromagnetic threat in the form of IEMI can be reduced by using absorber inside the resonant structures.

Edited by: F. Gronwald

Reviewed by: two anonymous referees

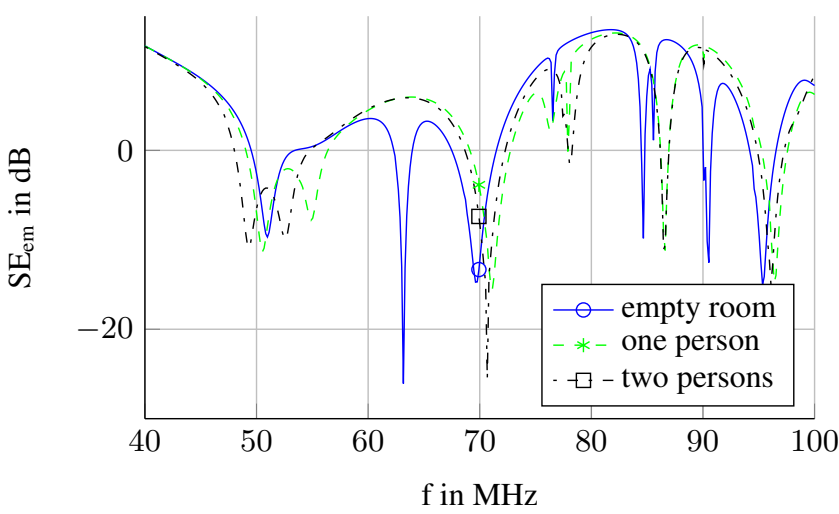

Figure 9. CEM results for SE with and without persons inside the room.

\section{References}

Dawson, L., Dawson, J. F., Marvin, A. C., and Welsh, D.: Damping resonances within a screened enclosure, IEEE Trans. Electromagn. Compat., 43, 45-55, 2001.

Ihsan, Z., Lubkowski, G., Adami, C., and Suhrke, M.: Characterization of the absorbing material used in EMC experiments, in: Proc. EMC Europe 2011 York, 774-777, 2011.

Izzat, N., Craddock, I. J., Hilton, G. S., and Railton, C. J.: Analysis and realisation of low-cost damped screened rooms, IEE Proceedings-Science, Measurem. Technol., 145, 1-7, 1998.

Nicolson, A. M. and Ross, G. F.: Measurement of the Intrinsic Properties of Materials by Time-Domain Techniques, IEEE Trans. Instrum. Meas., 19, 377-382, 1970.

Olyslager, F., Laermans, E., De Zutter, D., Criel, S., De Smedt, R., Lietaert, N., and De Clercq, A.: Numerical and experimental study of the shielding effectiveness of a metallic enclosure, Electromagnetic Compatibility, IEEE Transact., 41, 202-213, 1999.

Parr, S., Dickmann, S., and Rambousky, R.: Damping resonances of a screened enclosure using absorbing material, in: Electromagnetic Compatibility (EMC EUROPE), 2012 International Symposium on, 1-5, doi:10.1109/EMCEurope.2012.6396853, 2012. 